\title{
AN EXAMINATION OF MULTIDIMENSIONAL POVERTY PROFILE IN LIMPOPO, SOUTH AFRICA: IMPLICATION FOR USING CBMS GENERATED DATA IN LOCALISING SUSTAINABLE DEVELOPMENT GOALS, 2030
}

\author{
Grace Bicha Oloo
}

Institute for Rural Development, University of Venda, South Africa

\begin{abstract}
This study sought to profile multidimensional poverty in Tzaneen Local Municipality in Limpopo province in South Africa. The objective was to profile multidimensional poverty and further demonstrate the implication of Community-Based system (CBMS) generated data in localizing Sustainable Development goals 2030 at the municipality level. Consultative and CBMS design approach was adopted in the study. Administered household questionnaire was used to census 1,534households in Tzaneen Local Municipality Ward1. Indicators for poverty measurements were generated in partnership with local municipality and aligned to relevant sustainable development goals 2030. Data was captured using Excel software and imported to CSPro6.3 software for analysis. Community-Based Monitoring-National Research Database (CBMS-NRDB) software was used to generate poverty maps. Community validation approach was used to authenticate the study findings. We conclude that CBMS can generate multidimensional poverty profile and maps which can be used to localize Sustainable Development goals at municipality levels. We recommend that the local municipality use CBMS generated data to profile multidimensional poverty and as a baseline for localizing Sustainable Development goals 2030.
\end{abstract}

Keywords: Poverty, Sustainable development goals, community-based, South Africa

\section{Introduction}

The study sought to profile community-based multidimensional poverty and to examine the implication of the generated data in localizing Sustainable Development goals (SDGs) 2030.Poverty is an important, universal human problem as evidenced from its position on the world development agenda such as Sustainable Development goals 2030(United Nations,2015). Studies have shown that numerous strides have been made in poverty reduction in line with Millennium Development Goals(MDG, 2015). However, according to the World Bank, more than one billion people still live on less than $\$ 1.25$ per day. In addition, $70 \%$ of those living on less than $\$ 1.25$ per day are women. Almost half of the population of Sub-Saharan Africa survives at that income level (World Bank, 2016).In South Africa for example, years of active discriminatory policymaking and neglect has resulted in high levels of inequality, characterized by extreme wealth on one hand and desperate poverty on the other (The Studies in Poverty and inequality Institute \{SPII\}, 2006;Bhorat and Kanbur, 2005). On the other hand, one billion poor were raised out of extreme poverty between 1990 and 2013 (World Bank, 2016). This report demonstrates that elimination of extreme poverty is a realistic prospect. The trend in eradication of poverty, therefore, is one of the top priorities for the government of South Africa (Oosthuizen, 2011; Statistics South Africa, 2007). This demonstrates that information on poverty situation is vital for assessing progress out of poverty and for evidence-based policy development (Statistics South Africa, 2008; World Bank, 2016).A United Nations report, state that to effectively track progress on the SDGs, accessible, reliable, timely and disaggregated data at all levels is required. Regrettably this type of data is a major challenge to national and international statistical systems as statistical capacity still needs strengthening worldwide. Furthermore, the 
global statistical community is working to modernize and strengthen statistical systems to address all aspects of production and use of data for the SDGs (UN, 2017)

Development practitioners have recently realized that their efforts have not yielded the desired results partly due to inadequate information on poverty (UN,2008). Furthermore, research and experience reveal that workable follow up mechanisms were weak without disaggregated data for planning and implementation (Orim,2017;Robb,2017). Moreover, Meth, (2006) argue that conceptualization and relating it to both the execution and the interpretation of the surveys that provide the data for studies into the incidence of poverty is a challenge. It is in this respect that the United Nations, (2015) committed to enhance capacity building support in the developing countries to increase availability of high quality, timely and reliable data disaggregated by income, gender, status, disability, geographic location and other characteristics relevant in national contexts by 2020. Community-based monitoring System (CBMS) tries to address these gaps by providing timely and reliable data disaggregated across population sub-groups, and by geo-political levels (Reyes and Due, 2009).

There are generally two main approaches used to measure poverty. These are money metric and non-money metric measures. Money metric measures are cardinal measures of poverty which centres on income and expenditure to determine poverty. It measures levels of living by money required to sustain a household, a group or a community (Moser and Felton, 2007). On the other hand, poverty can be seen as multi-Dimensional, encompassing other issues such as housing, health, education, access to services and other avenues of accessing resources in a broader sense (SPII,2007). A similar pattern is captured in Sustainable Development goals 1 to 8 in terms of, poverty, hunger, food security, health, education, gender, water, sanitation, energy, productive employment and climate change (UN,2015). Furthermorethe 2030 agenda requires follow- up and review processes to be informed by country-led evaluation and the need to build capacity for national data systems and evaluation. The agenda is built on the principle of leaving no one behind, discreetly promoting the inclusion of all poor persons. It calls for a robust follow-up and review process to track progress toward the Sustainable Development Goals (SDGs) through innovative action (UN),2015). The community based monitoring system indicators follow a similar pattern to Sustainable Development goals 1 to 8 and perceives poverty as multidimensional. Moreover, if done on a continuous basis, community-based monitoring system (CBMS) can produce a panel data usable for monitoring progress toward the achieving Sustainable Development goals agenda. In addition, community-based system is like a household census and is not a sample- based methodology which insures that no one is left behind.

The multiplicity of poverty dimensions has brought about the development of various approaches to poverty measurement (Alkire and Sarwar ,2009;Asselin,2009;Tarozzi\& Deaton,2007). Ravallion (2001) highlights the numerous discussions and polarizing debates regarding poverty measurements as reactions towards them tend to vary depending on the impact on certain interest groups. However, several researchers have noted that, all approaches are equally useful although some may work better than others depending on the research situation at hand (Alkire,2011; Atkinson andBouurguignon,1982; Hume, 2011). Statistics South Africa (2008) emphasised that accountability and transparency decisions on poverty measures should be anchored on the relevancy of approaches and the purpose of measurement. It is worth noting that in South Africa,poverty measuring methodology is institutionalised at national government levels. However there exists inadequate information at local government levels. In spite of the efforts made by the South African governemnt to conduct regular poverty monitoring surveys, its efforts can best be regarded as limited and isolated (May,2001;Hirschowitz, et al 2000). Moreover, the macro-level analyses camouflage differences in poverty at local municipal conditions. The lack of information on the share of the population living in poverty at household levels hinders evidencebased policy making (Scott,2005).Community-based monitoring system provides a consistent monitoring framework that enhances local planning, budgeting and implementation at household levels (Reyes and Due, 2009). It is against this background that research was conceived to profile multidimensional poverty in Limpopo province in South Africa and to examine the implication of the generated data in localizing Sustainable Development goals 2030. 


\section{Objectives of the Study}

The objectives of the study are as follows:

- To diagnose the extent of multidimensional poverty at Tzaneen Local Municipality Ward 1, and

- To examine the implication of CBMS generated data in localizing Sustainable Development agenda 2030.

\section{Methodology}

The implementation of the community based monitoring system methodology was used following a series of steps. The steps are explained in detail below.

\section{Advocacy/Organization}

Data requirement was evaluated in conjunction with the Local Economic Development (LED) officials at the local municipality to identify existing gaps. A detailed work plan was developed that details the roles and commitment of all parties. Indicators for conduct of the study were developed in conjunction with the Local Economic Development office and aligned with the data requirements. The indicators were also aligned with the national and provincial strategies on poverty reduction.

\section{Study Design and Data Collection}

Data collection process was undertaken through a census covering 1,534 households in the 8 villages across all localities by twenty-three trained enumerators. The traditional leaders provided respective household listings that were used to establish the authenticity of the households. Enumerators underwent training which took four days plus one-day field orientation and a two-day field mentorship prior to actual data collection. The researcher employed a convergent design approach where equal priority was given to both quantitative and qualitative strands(Angell and Townsend, 2011). This approach provided a better understanding of the causes of poverty, type and location of affected households. Household profile questionnaire and Ward level administrative questionnaires were used to collect data. The two questionnaires were accompanied by two manuals. Secondary data was collected from various literatures, research journals, periodicals, government official reports, Statistics South Africa, and the Internet. Collected data was edited and captured in an Excel spread sheet ready for consolidation, coding and analysis.

\section{Data Processing and Analysis}

Data processing was done using pre-set poverty dimension, indicators and formula. The CSPro 6.3 software was used to create data dictionary which described the organization of the data file. The following formula was used to calculate proportions per indicators.

$\{\mathrm{X} \%=(\mathrm{Z} / \mathrm{Y}) * 100\}$

Where $\mathrm{X} \%=$ Proportion, $\mathrm{Z}=$ Magnitude unmet needs, $\mathrm{Y}=$ Total number

\section{Map Digitization, Processing and Mapping}

Encoded dataset was imported using community-based monitoring systems- Natural resources database [CBMS -NRDB] software to generate poverty maps. Household unmet needs were mapped using core indicators. In addition, four color schemes namely green, light green, light red and red were used in the legend to display the magnitude of vulnerability. The following formula was used to determine the ranges. 
1st range maximum value: ((Ward value [X.Y]-minimum value of all villages [0]) / 2) + minimum value of all villages [0])

2nd range minimum value: $=1$ st range maximum value

2nd range maximum value $=$ Ward data $[X . Y]$

3 rd range minimum value: $=2$ nd range maximum value

3rd range maximum value: (maximum value of all villages [100] - Ward data [X.Y.]) / $2+$ Ward1data([X.Y.]

4 th range minimum value: $=3$ rd range maximum value

4th range maximum value: 100 (always 100 since the percentages ranges from 0-100)

\section{Data Validation}

The results of the census were presented in a community forum where the extent of multidimensional poverty was discussed, disorganized and explained. At this point, appropriate interventions were also identified. Presentation of the data to the community was vital to ensure accuracy.

\section{Ethical Considerations}

The researcher communicated the aims and purpose, the implications, and possible risks for involvement in the study to respondents. This was done in order to uphold research ethics, ensure conformity to the ethical requirements and secure informed consent. Approval to undertake the study was sought and granted from the local municipalities and local structures. Even though full participation was required during the exercise, the respondents were informed of the fact that they had the right to withdraw from the study at any time.

\section{Results of the Study}

\section{Employment}

Table 1 below shows that of the 1,534 households interviewed, and average of some 38 to 39 percent worked for wages as either employed or casual workers. Of those who worked for wages 62.2 percent were male and 37.6 female. Out of the casual 60.8 percent were female and 39.2 percent were female, for every 100 employed heads of households 37.6 percent were likely to be female. 57.5percent out of those interviewed were unemployed. Overall 60.3percent of the unemployed heads of households were most likely to be female compared to 55.5percent male counterparts. However, of the unemployed category, 56.1 percent were likely to be male while 43.9percent were female. Within the self-employed category 54.9 percent were male and 45.1 percent were female. This Indicates that for every 100 heads of household who were self-employed, 54.9percent were likely to be male. Yet for unpaid family workers the majority were female at 75.0 percent compared to their male counterparts at 25.0 percent. The unpaid family workers formed only 0.3 percent percent of in all categories. Self-employed were 3.3 percent while 9.7 percent were casual workers. Overall, the level of unemployment exceeded the levels of the self-employed and employed. Further investigations showed that unemployed respondents depend on income from pensions, government grants and remittance from family members working in urban centres. The self-employed women were engaged in selling vegetables, fruits and other types of food in the villages. To ensure that benefits of growth and employment creation are more equitably distributed, the local municipality needs to ensure that integrated development planning places the growth of labor- intensive sectors at its core. 
Table 1: Magnitude and proportion of household head, by employment status, by gender, Ward 1, G. Tzaneen, Limpopo, 2013

\begin{tabular}{|c|c|c|c|c|c|c|c|c|c|}
\hline \multirow[b]{2}{*}{ Job of head HH } & \multicolumn{3}{|c|}{ Magnitude } & \multicolumn{3}{|c|}{ Proportion by category } & \multicolumn{3}{|c|}{$\begin{array}{l}\text { Proportion by category to } \\
\text { total Households }\end{array}$} \\
\hline & Male & Female & Total & Male & Female & Total & Male & Female & Total \\
\hline Employed & 270 & 163 & 433 & 62.4 & 37.6 & 100.0 & 30.3 & 25.4 & 28.2 \\
\hline Casual worker & 90 & 58 & 148 & 60.8 & 39.2 & 100.0 & 10.1 & 9.0 & 9.7 \\
\hline Unemployed & 495 & 387 & 882 & 56.1 & 43.9 & 100.0 & 55.5 & 60.3 & 57.5 \\
\hline Self employed & 28 & 23 & 51 & 54.9 & 45.1 & 100.0 & 3.1 & 3.6 & 3.3 \\
\hline $\begin{array}{l}\text { Unpaid family } \\
\text { worker }\end{array}$ & 1 & 3 & 4 & 25.0 & 75.0 & 100.0 & 0.1 & 0.5 & 0.3 \\
\hline Other ( specify) & 8 & 8 & 16 & 50.0 & 50.0 & 100.0 & 0.9 & 1.3 & 1.0 \\
\hline Total & 892 & 642 & 1,534 & 58.2 & 41.9 & 100.0 & $\begin{array}{l}100 . \\
0\end{array}$ & 100.0 & 100.0 \\
\hline
\end{tabular}

\section{Education Institution Attendance}

Table 2 shows education institution attendance by age category. The results show that of 487 children of age 3 to 5 years old in study sites, 82.3percent were not attending any education institution. The study shows that relatively few children attended pre-school. This could be due to limited public transportation due to bad road conditions and inadequate foundation developmental schools. In computing non-attendance ratio for ages 6 to 18 years old combined ,the result show the lowest non-attendance ratio of 13.1percent out of a total of 1,601 in this age range category. The high attendance levels were mostly likely due to the fact that educational enrollment and attendance for children from age 6-18 years old in South Africa was made compulsory. Education at these levels is free and meals are provided to the students. Furthermore, single mothers are able to access monthly child grant. At this age, children are more likely to walk to schools within or outside the villages. In addition, the government provides 60.0percent funding to rural poor schools. Further investigation revealed that children who did not attend pre-school were most likely to stay at home with their parents and/or grandparents.

Results in Table 2 show that of 2,218 of ages 19 to 35 years old, 76.1 were not attending any educational institution. Further investigations showed that this could be due to teenage challenges such as teenage pregnancies, financial issues, social issues and lack of interest. Further investigation revealed that the National Student Financial Aid Scheme (NSFAS) provides loans and bursaries to students from poor backgrounds who wish to study at South Africa's public higher education institutions.

Figure1 shows the ages 3-5 years old attendance by village where Senakwe, Pelane, Mauntlala Patamedi Moloko and Manswa villages need urgent attention by local municipality. 
Table2. Magnitude and proportion of persons, by school attendance, Ward 1, G. Tzaneen, Limpopo, 2013

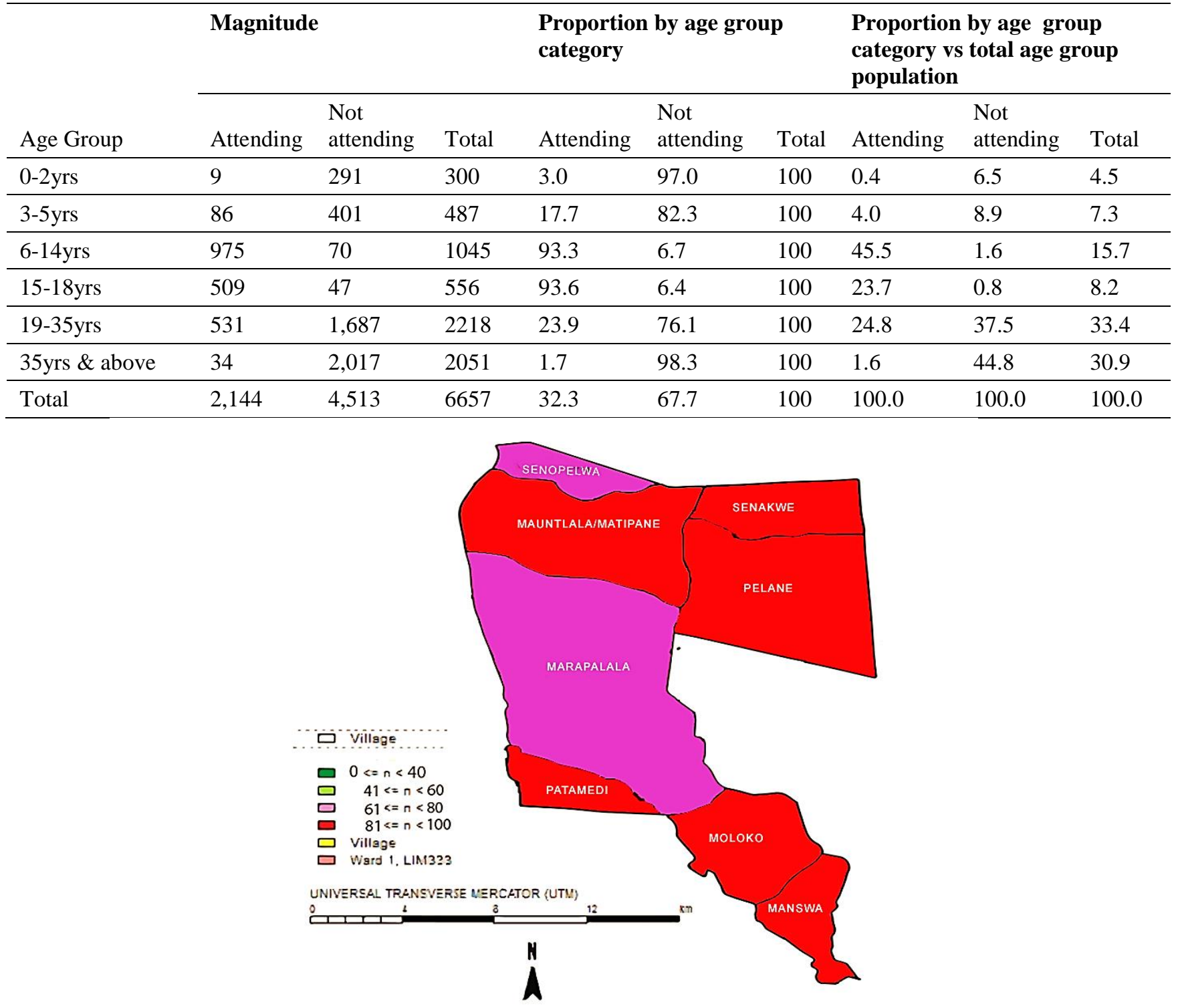

Figure 1. Proportion of age 3 -5 years old not attending education institution by village, Ward 1, G. Tzaneen, Limpopo, 2013

\section{Energy Accessibility}

Table 3 below shows that of the 1,534 households interviewed, 86.51percent used firewood energy source for cooking and 91.53percent for heating. 94.5percent received their source of energy from Electricity supply commission of South Africa (Eskom), 0.93percent from solar and 4.29percent firewood. However, about 10.00percent would normally use candle/kerosene lamp or other sources other than electricity for lighting, 0.13 percent used paraffin for cooking and 0.86percent would normally use charcoal/solar. Only 5.61percent households would normally use electricity for heating. Further investigation revealed that this could be due to the fact that even though South Africa rural households receive subsidized electricity tariffs, provided as a free basic allowance, rural households tend to incorporate electricity into their domestic energy, primarily using electricity for lighting. Majority were most likely to use energy mainly from the traditional sources such as fuel-wood and cow dung for multiple purposes, such as cooking, water-heating and lighting while others use paraffin (kerosene). Additional investigation showed that the employed and self-employed moderately relied on energy from electricity grid but harvested and purchased fuel-wood to supplement electricity for domestic use 
while those in the unemployed category relied mainly on traditional sources of energy such as wood fuel. Figure 2 below shows that Marapalala, Manswa and Patamedi villages need urgent attention followed by Senakwe and Moloko villages.

Table 3. Magnitude and proportion of energy accessibility per household. Ward 1, G. Tzaneen, Limpopo, 2013

\begin{tabular}{|lll}
\hline Energy access & Magnitude & Proportion \\
\hline Eskom & 1322 & 94.5 \\
\hline Solar & 13 & 0.93 \\
\hline Firewood & 60 & 4.29 \\
\hline Candle/ lamp etc & 153 & 10.0 \\
\hline Firewood as cooking energy source & 1327 & 86.51 \\
\hline Electricity as cooking energy source & 195 & 12.71 \\
\hline Paraffin and solar & 4 & 0.26 \\
\hline Firewood as heating energy source & 1404 & 91.53 \\
\hline Charcoal/ solar and other & 13 & 0.86 \\
\hline
\end{tabular}

Note: Multiple answers by households were obtained therefore the percentage does not add up to 100.

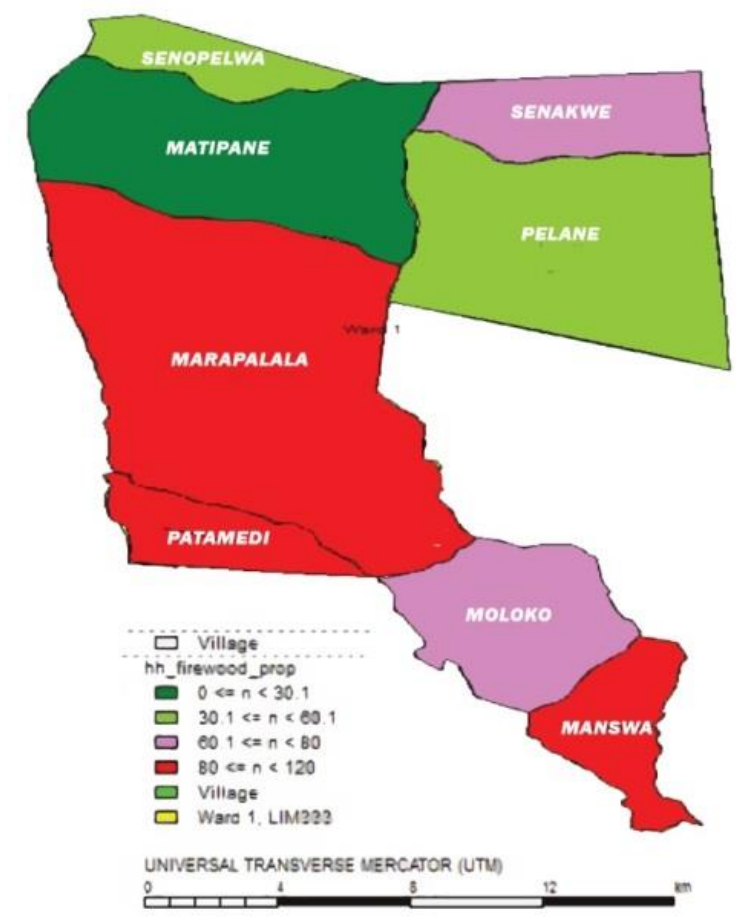

Figure2. Proportion of household using firewood as source of anergy for cooking by village, Ward 1, Tzaneen,

\section{Accessibility to Safe Drinking Water}

Table 3 indicates that an average of some 73 to 74 percent of 1,534 households had accessed unsafe drinking water from communal piped water, municipality water tank, and river / stream. This is because the taps were dry or there had not been any water in the tanks for a period up to three months due to broken pipes or lack for maintenance from Local municipality. Those who did not access communal, water tanks or water pipes in the yard were more likely to access contaminated water from river/ stream. Further investigation revealed that those who had no access to safe water fell under the unemployed and /or depended on social security for survival. Investigations also revealed that the average distance to the water source for 1 out of 5 households was above 
$1.7 \mathrm{~km}$. Of the households that did have access to water; further interrogation revealed that water was soiled and could not be drank. Figure 3 shows that Marapala, Moloko Manswa, Senoplelwa Pelane and Senakwe villages need urgent attention in relation to the indicators showing that the water issue was severe in majority of the villages.

Table 3. Magnitude and proportion of households by safe water accessibility and distance to water source, Ward1 Tzaneen, Limpopo, 2013

\begin{tabular}{|c|c|c|c|c|c|}
\hline \multicolumn{2}{|l|}{ Water accessibility } & \multicolumn{2}{|l|}{ Magnitude } & \multicolumn{2}{|c|}{ Proportion } \\
\hline \multicolumn{2}{|c|}{ Piped water inside house } & 3 & & \multicolumn{2}{|c|}{0.2} \\
\hline \multicolumn{2}{|c|}{ Piped water in Yard } & 41 & & \multicolumn{2}{|c|}{2.67} \\
\hline \multicolumn{2}{|c|}{ Communal piped water } & 1,058 & & \multicolumn{2}{|c|}{68.97} \\
\hline \multicolumn{2}{|l|}{ Borehole } & 72 & & \multicolumn{2}{|c|}{4.69} \\
\hline \multicolumn{2}{|l|}{ Water tank } & 215 & & \multicolumn{2}{|c|}{14.02} \\
\hline \multicolumn{2}{|l|}{ River/Stream } & 60 & & 3.91 & \\
\hline \multirow[t]{2}{*}{ Distance to water } & Observations & Mean & Standard Deviation & Min & $\operatorname{Max}$ \\
\hline & 1534 & 1.688889 & .8512335 & 1 & 5 \\
\hline
\end{tabular}

Figure 4. Proportion of households without adequate water source per village, Ward 1, G. Tzaneen, Limpopo, 2013

\section{Health Facility and Accessibility}

Table 5 below shows health accessibility, diseases and health facilities accessibility by household. Out of 1,534 household interviewed, some 42 to 43 percent had suffered various sicknesses a month prior to the study period. These diseases included cholera, diarrhoea, malaria and tuberculosis. These are expected in Tzaneen due to water and toilet situations. In addition, Tzaneen is a malaria prone area. Of those respondents, 89.11 percent were attended to by public hospitals while 89.7percentwent to public health hospitals for treatment, 39.9 percent attended clinics and 61.73 percent were treated by a nurse. The clinics are mainly mobile clinics that visit the Wards to attend to those who are not able to reach the hospitals. Out of the respondents, 11.93 percent had been treated by traditional healers, while 31.16 percent did not specify the type of treatment they received. Of those interviewed, 52.44 percent indicated that the money for medical treatment came from pocket and that it was not adequate. 86.06percent said that there was increase in medical cost due to inflation (75.44percent) with others simply saying increase in registration. Further investigations revealed that there was no hospital in Ward 1 and that households attended either public clinics or mobile clinics. 
Table 5. Magnitude and proportion of households, by sick members, sickness type, health facilities and medical cost, Ward 1, G. Tzaneen, Limpopo, 2013

\begin{tabular}{lll}
\hline Variables & Magnitude & Proportion \\
\hline $\begin{array}{l}\text { Sick members((Diarrhoea, Pneumonia, } \\
\text { Malaria and Cholera }\end{array}$ & 629.0 & 41.00 \\
\hline Health facilities by Household & & \\
\hline Hospital & 1367.0 & 89.11 \\
\hline Public Health & 1376.0 & 89.7 \\
\hline Public Clinic & 612.0 & 39.9 \\
\hline Over the counter & 486.0 & 31.68 \\
\hline Mobile clinic (Nurse) & 947.0 & 61.73 \\
\hline Traditional healer & 183.0 & 11.93 \\
\hline Other & 478.0 & 31.16 \\
\hline Other Concerns & & \\
\hline Inadequacy of medical fund & 805.0 & 52.44 \\
\hline Increase in Medical cost & 1321.0 & 86.06 \\
\hline Reason for increase( inflation) & 1158.0 & 75.44 \\
\hline
\end{tabular}

Note: Multiple answers by households were obtained therefore the percentage does not add up to 100. Eg: households using multiple health facilities.

\section{Discussions}

The purpose of this study was to examine multidimensional poverty in Tzaneen Local Municipality and to further demonstrate the implication of using generated data in localizing Sustainable Development goals 2030. Community -based monitoring system was used to capture the multiplicity of poverty conditions in the study sites. Study results demonstrate that CBMS methodology can be used to profile multidimensional poverty at local municipality.

The study results revealed that 72.88 percent of households interviewed had unsafe drinking water. The CBMS findings portray similar pattern with Integrated Development Plans (IDP), (2012), which state that approximately 26.00 percent of the population did not have access to clean water.

The CBMS findings further show that of the 3-5 years age category 82.3 percent were not attending any education institution. This is an area of concern considering that this is the foundation level for child development. On the other hand, an average proportion of education attendance for age 6-14 and 15 to 18 years old was 93.3percent and 93.6percent respectively. Education attendance level at ages 19 -35 years old seems to have dropped to 23.9 percent with 76.1 percent not attending. The finding above follows a similar pattern with the South Africa Annual Performance Plan 2013-2014 which indicate that drop out in grades 9, 10 and 11 was high. The National Planning commission,2011, argues that the promotion of learners who were not ready in primary and early secondary phases led to substantial dropout before grade 12 (equivalent to Cambridge HIGCSE). In its vision for 2030, the South Africa government plans to set up early childhood development centers that would be properly monitored (NPC,2011). The results have similar findings by Cloate, Sheppard and Van Schalkwyk, (2016) who state that South Africa tertiary participation is too low partially because it does not have a post-secondary college even though there is high primary and secondary participation.

Study results show that 86.51 percent of households used firewood energy source for cooking and 91.53percent used it for heating. Further investigation revealed that South Africa rural households receive subsidized electricity tariffs, provided as a free basic allowance. However rural households primarily use electricity for lighting. Majority were most likely to use energy mainly from the traditional sources such as fuel-wood and 
cow dung for multiple purposes, such as cooking, water-heating and lighting while others use paraffin (kerosene). In addition, the self-employed moderately relied on energy from electricity grid but harvested and purchased fuel-wood to supplement electricity for domestic use while those in the unemployed category relied mainly on traditional sources of energy such as wood fuel. Programmes that promote restoration of rural forests should work closely with local municipality to investigate environmental challenges resulting from deforestation for wood fuel by residents.

\section{Implication of the Use of CBMS Generated Data in Localizing Sustainable Development, 2030}

The results highlight implication for use of generated data in both practical and future research.

\section{Implication for Practice}

The first major practical implication is that the study results provide much needed empirical data on multidimensional poverty realities at local levels in terms of who are the poor, where they are and what contributes to their poverty. The Community Based-Monitoring System generated data is therefore vital for formulating appropriate Sustainable Development Goals (SDGs) by providing the basis for allocation of resources and targeting the right beneficiaries per dimension by local municipality and by other poverty focused organizations. This finding can be used to further respond to concerns raised by the UN, 2015 that more than 700 million people still live in extreme poverty and are struggling to fulfill the most basic needs like health, education, and access to water and sanitation.

A second important implication is derived from the uniqueness of the CBMS generated data in terms of disaggregation across population sub-group and geo-political groups. An analysis of such data can be used to assess policy implication by sub-groups and geo-politics and the development planners to make informed decisions by gender, age-groups, location based on the actual data. This finding responds to the concern by UN, 2015 thatachieving the Sustainable Development goals (SDGs) effectively, in a fast, efficient, impactful and lasting way will require innovative action( UN,2015)

A third implication is that generated data capture multiple dimensions of poverty based on a set of carefully selected indicators. In Sustainable Development goals 2030, these similar patterns of indicators are captured in goals 1 to 8 . Moreover, the usage of CBMS-NRDB generated maps which show a simple color scheme on the severity of situations makes it easier to interpret and understand both the magnitude of poverty and provide quick reference on beneficiary targeting. Such information can be used by planners to prioritize projects through appropriate budget allocation. The findings respond to several calls by UN, 2015 that the 2030 agenda requires follow up and review processes to be informed by country-led evaluation and the need to build capacity for national data systems and evaluation.

The fourth important implication is that CBMS generated data if conducted on ongoing basis can produce panel data that could be used by local planners to monitor the impact of interventions disaggregated across subgroups or geo-political levels. The data can therefore provide baseline information for preparing progress reports. This answers the call by UN, 2015 that the 2030 agenda that calls for a robust follow-up and reviewing process to track progress toward the Sustainable Development Goals (SDGs).

The fifth implication is that community -based monitoring system is grounded on the principle that poverty can best be understood through the lives and experiences of the poor themselves. The system captures various dimensions in an ongoing dynamic way and allows the poor themselves to validate the information in collaboration with local officials and planners. This makes it easier to diagnose the extent and nature of poverty (Reyes and Due, 2009). This corroborate the over two years of intensive public consultation, engagement done during the SDG 2030 process with civil society and stakeholders around the world with particular attention to the voices of the poorest and most vulnerable to come up with the agenda for 2030( UN, 2015). Participatory 
processes ensured that programmes were aligned with local needs, building local capacity, and ensured sustainability (UN, 2017)

\section{Implication for Future Research}

While we have generated a number of what we believe are useful results given the rigorous nature of the CBMS methodology, this study will be more comprehensive if data is collected from a number of local municipalities. Secondly, our study offers the opportunity to refine and expand the usage of CBMS data to other areas related to Sustainable Development goals 2030 such as climate change and an in-depth study on energy.

\section{Limitations and Critique of the CBMS}

These findings are based on the study on one Ward; there is therefore need for a rollout to other local municipalities for a more comprehensive conclusions. Secondly, with regard to data limitation, it is worth noting that certain characteristics for instance, employment and civil status were only available at the household level and not at the members level. Such Information should be included at member level to get a more comprehensive data and conclusions. Finally, CBMS should be viewed as a complement and not a substitute, to national-level sample surveys. Furthermore, indicators, data-collection methodology and validation must be adapted to local conditions and developed over time. Critical to its success is the fact that enabling conditions need to exist for CBMS to be effectively institutionalized (Reyes and Due, 2009).

\section{Conclusions and Recommendations}

Information on poverty, is vital for assessing progress and evidence-based policy development .The CBMS generated data results reveals that there exist multidimensional poverty at local municipality level which can be used to track progress on Sustainable Development goals at municipality levels (Statistics South Africa, 2008; World Bank, 2016). However indicators, data-collection methodology and validation must be adapted to local conditions.

Accessible and reliable disaggregated data is required at all levels to effectively track progress on the SDGs. Study results demonstrated that CBMS generates data can be disaggregated across population sub-group and geo-political groups. An analysis of such generated data can allow policy-makers and the development partners to make informed decisions based on the actual data. However, statistical capacity and systems will need to be strengthened at local municipality levels to address all aspects of production and use of data for the SDGs(UN, 2017).

SustainableDevelopment goals one to eight encompasses issues such as housing, health, education, water, toilet, health, gender and energy. Study results demonstrate that a similar pattern is captured by CBMS generated data. However, CBMS methodology should be viewed as a complement and not a substitute, to national-level sample surveys.

We recommend that the local municipality consider using CBMS generated data as a baseline for profiling multidimensional poverty and assessing progress towards achieving Sustainable Development agenda. CBMS should however be used as complementary to other study methods and not as a stand-alone method.

\section{Acknowledgement}

This work was carried out with a grant from the Poverty and Economic Policy (PEP) Network supported by the Government of Canada through the International Development Research Centre (IDRC), and the Canadian International Development Agency. 


\section{References}

Addison T, Hulme, D, Kanbur R., 2011, Poverty dynamics-interdisciplinary perspectives. Oxford university press, Oxford.

Alkire, S., Foster J.E., 2011, Counting and multidimensional poverty measurement. Journal of public economics 95, 476-487.

Alkire,S. and Sarwar, B.M., 2009, Multidimensional Measures of Poverty \& Well-being. Report Working Paper. Department of International Development Oxford. United Kingdom.

Atkinson, A, B., Bourguignon, F., 1982. The comparison of multidimensional distributions of economic status. Review of economic studies 49, $183-201$.

Angell, B. and Townsend, L., 2011, Designing and conducting mixed methods studies. Workshop for the 2011 Society for Social Work and Research Annual Meeting, Institute of Health, Health Care and Aging Research of Rutgers School of Social Work, The State University of New Jersey.

AsselinL.M .2009. Analysis of multidimensional poverty theory and case studies Springer Science and Business Media, LLC, 233 Spring Street, New York, NY 10013, USA

Bhorat, H., and Kanbur, R., 2005, Poverty and well-being in post-apartheid South Africa: an overview of data, outcomes and policy, working Paper No. 05/101, Cape Town: Development Policy Research Unit, University of Cape Town.

Cloete, N., Sheppard, C., \& Van Schalkwyk, F., 2016, Fees and sustainable developmentmoving the higher education fees debate from ideology to evidence. Centre for higher education transformation, Pretoria

Hirschowitz, R., Orkin, M., and Alberts, P., 2000. Key baseline statistics for poverty measurement. In R. Hirschowitz (Ed.), Measuring poverty in South Africa. Pretoria: Statistics South Africa, pp. 5-52.

Integrated Development Plans.,2012, Integrated development plans 2012/13-2016/17 [Draft]. Tzaneen: Tzaneen Local Municipality.

May, J.,2001, An elusive consensus: Definitions, measurement and analysis of poverty. In A. Grinspun (Ed.), Choices for the poor: Lessons from national poverty strategies. New York: United Nations Development Programme, pp. 23-54.

Meth, c. 2006. Income poverty in 2004: A second engagement with the recent van der berg et al figures. Working paper no. 47. Durban: school of development studies, university of Kwazulu-Natal.

Moser, c. \& Felton, A., 2007. The construction of an asset index measuring asset accumulation in Ecuador

National Planning Commission., 2011, National development plan vision 2030, Pretoria, South Africa: The Presidency.

Oosthuizen, M., 2011, Estimating poverty lines for South Africa. Retrieved from www.infr.gov.za on 12/7/17 from Department of Social Development.

Orim, S.,2017, Strategies for attaining sustainable development goals for persons with disabilities: National recommitment to sustainable inclusive education in south-south geopolitical zone of Nigeria. Proceedings of socioint 2017- 4th international conference on education, social sciences and humanities 10-12 July 2017Dubai, UAE.ISBN: 978-605-82433-1-6 1353

Ravallion, M. 2001. Poverty lines: economic foundations of current practices. World Bank.

Reyes, C., \& Due, R., 2009, Fighting poverty with facts: Community-based Monitoring system. Ottawa, ON: International Development Research Centre.

Robb , C, R.,, 2017 . Powering the sustainable development goals in Africa: rewriting the global rules, Huffington post.

Scott, C.,2005, Measuring up to the poverty measuring problems: The role of statistics in evidence based policy making. UK: London school of Economics.

SPII ,2005, The Measurement of Poverty in South Africa Project: Key issues from statistics South Africa (2000) Measuring poverty in South Africa, Pretoria: Statistics South Africa.

Statistics South Africa,2007, General household survey 2006. Pretoria South Africa: Statistics South Africa.

Statistics South Africa,2008, Community Survey 2007: methodology, processes and studies in poverty and inequality. Johannesburg, South Africa: Statistics South Africa. 
Statistics South Africa,2011, General household survey 2010 (revised version). Pretoria South Africa: Statistics South Africa.

Tarozzi, A., \& Deaton, A., 2007, Using census and survey data to estimate poverty and inequality for small area. The review of Economic Statistics, 61(1), 146-149.

UN,2017, Sustainable development goalsreport $2017 . \quad$ Accessed from https://www.un.org/development/desa/publications/sdg-report-2017.html on 3-8-17

UN,2015,Sustainabledevelopment $\quad$ goals2030. Accessed from http://www.un.org/sustainabledevelopment/sustainable-development-goals/. Accessed on12/3/17

World Bank, 2016, Poverty and shared responsibility. Taking on inequality. World Bank. Washington DC.USA. 